\title{
El cancionero revelado de la abadesa franciscana Juana de la Cruz (1481-1534). Edición y comentario
}

\author{
Pablo Acosta-García* \\ Heinrich-Heine-Universität Düsseldorf \\ pablo.garcia.acosta@gmail.com
}

Recepción: 27/05/2021, Aceptación: 07/07/2021, Publicación: 22/12/2021

\begin{abstract}
Resumen
En las siguientes páginas edito y comento un corpus inédito de cinco canciones vinculadas a la abadesa franciscana Juana de la Cruz (1481-1534). Además de un texto que se transcribe siguiendo criterios filológicamente fiables, proporciono una descripción material de la fuente y realizo un estudio métrico de las composiciones. Por otro lado, desde la ladera de su interpretación histórica, hago un breve comentario teológico de cada una de las piezas, que las propone como parte de la producción lírica franciscana europea, a la vez que las contextualizo en la predicación visionaria de la abadesa en su contexto cisneriano.
\end{abstract}

\section{Palabras clave}

Juana de la Cruz; reforma observante; franciscanismo femenino; predicación femenina; Libro del conhorte; lírica religiosa; laude.

* El presente artículo ha recibido financiación del programa de investigación e innovación de la Unión Europea Horizon 2020 a través del "grant agreement" número 842094 (= This article has received funding from the European Union's Horizon 2020 research and innovation programme under the Marie Skłodowska-Curie grant agreement No. 842094). Agradezco a Vicenç Beltrán, Nigel Palmer, Carolyn Muessig, Rebeca Sanmartín Bastida, José Antonio Ramos Arteaga, a Marco Grilli y a sus compañeros del "Laboratorio di Conservazione" del Archivio Apostolico Vaticano y, por último, a los bibliotecarios de la Biblioteca de la Universidad de La Laguna (que me ayudaron en tiempos dolorosos) su ayuda con diversos aspectos de este artículo. A su vez, agradezco las sinergias a los miembros del proyecto de investigación 'Catálogo de santas vivas (1400-1550): hacia un corpus completo de un modelo hagiográfico femenino’ (PID2019-104237GB-I00) del que soy miembro. 


\begin{abstract}
English Title. The Ecstatic Chansonnier of the Abbess Juana de la Cruz (1481-1534). Edition and Commentary.

In the following pages I provide a Philological edition of five unpublished songs linked with the production of the Franciscan abbess Juana de la Cruz (1481-1534). I study first the source from a material point of view, and then develop a metric analysis of the songs, putting them in the context of the Franciscan lyrical poetry at a European level. On the other hand, I make a brief theological commentary of each of the songs, contextualizing them in the visionary preaching activity of the abbess.
\end{abstract}

\title{
Keywords
}

Juana de la Cruz; Observant Reform; Female Franciscanism; Female Preaching, Sermons; Libro del Conhorte; Religious Lyrical Poetry; laude.

Descendi del cielo, del cielo Inpirio.

Vine fasta el ssuelo como peregrino. Bivi ssin abrigo y no lo penssáis. ¡Cuán mal lo miráis, cuán mal!

El grupo de canciones del que he tomado esta estrofa debe ser considerado como el primer corpus lírico castellano de ámbito monástico femenino ligado explícita e inequívocamente al nombre de una mujer. Juana de la Cruz (1481-1534) las entonó en la casa religiosa de la que fuera abadesa desde 1509, el Convento de Santa María de la Cruz (Cubas de la Sagra, entonces Toledo) en una o varias ocasiones durante los trece años que duró su predicación visionaria (1508-1520). ${ }^{1}$ Los can-

1. Esta información sobre los años de predicación de la abadesa se da en su primera hagiografía, Vida y fin de la bienaventurada virgen sancta Juana de la Cruz, monja que fue professa de quatro botos 
tos se transcriben al final del segundo de los dos volúmenes manuscritos que se encuentran en el Archivio Apostolico Vaticano con la signatura única Congr. SS. Rituum Processus 3074 (de ahora en adelante, manuscrito del Vaticano), específicamente en los ff. 731v-733v. ${ }^{2}$ Estos guardan la segunda copia existente de la recopilación de setenta y dos sermones de Juana conocida ya de antiguo como Libro del Conhorte (de ahora en adelante, Conhorte), que fueron enviados al Vaticano en 1665 directamente desde el convento de Cubas de la Sagra durante el proceso de canonización de la abadesa (García Andrés 1999: I, 69 y 142). A pesar de esta conexión directa con el lugar de producción de la compilación, de ser el único testimonio no solo de las canciones que enseguida comentaré, sino también de pasajes textuales únicos, esta fuente ha sido considerada como secundaria frente al otro testimonio de los sermones, el manuscrito del Conhorte que se encuentra en la Real Biblioteca de El Escorial con la signatura J-II-18, que fuera editado por García Andrés (1999). ${ }^{3}$

Antes de comenzar a ahondar en las particularidades de estas canciones, quizá conviene aclarar las circunstancias históricas en las que la abadesa predicaba y en la que estos versos se transmiten primariamente. Debemos situar la época de su canto poco después de la reforma de una comunidad terciaria franciscana a la que Juana entró en su nińez y que ella misma ayudó a reformar (Grańa Cid 2004: 309-310 y 2017; Muñoz Fernández 2016). Esta transformación se integra en la campaña de 1495 de los Reyes Católicos, por la que encargan al Cardenal Francisco Ximénez de Cisneros la reforma de las todas las comunidades femeninas de Castilla (García Oro 1971: 253-254). ${ }^{4}$ El caso del proceso de institucionalización del convento de Juana de la Cruz es paradigmático, porque es una casa que pasa en por tres fases diversas: tempranamente de beaterio a convento de la Tercera Orden Regular de San Francisco (c. 1464) y de este, coincidiendo con el inicio del abaciato de Juana (1509), a convento franciscano seguramente bajo una variación de la Regla urbanista (Acosta-García 2021a: 8-9). Es decir, que los cambios últimos incluían la adopción del

en la orden del señor sant Francisco, en la qual vivió perfeta y sanctamente, que se encuentra en una única copia en la Biblioteca Real de El Escorial con la signatura K-III-13. Cito aquí por la edición de Luengo Balbás y Atencia Requena (2019: ff. 28r y 31r). Para una comparación del modelo de santidad encarnado por Juana en esta narración en el contexto hagiográfico de su época, véase Acosta-García (2021b). La figura de Juana de la Cruz fue puesta en valor por la obra de Surtz (1990 y 1995), que ha dado lugar a una creciente bibliografía sobre la abadesa visionaria y su obra.

2. El primer volumen comprende de los ff. 1 al 453v y el segundo de los ff. 454 al 733v.

3. La descripción clásica del manuscrito la da Zarco (1924-1929: II, 99-105). La del Catálogo en línea de la Real Biblioteca de El Escorial aporta información suplementaria: <https://rbmecat. patrimonionacional.es/cgi-bin/koha/opac-detail.pl?biblionumber $=738 \&$ query desc $=\mathrm{kw} \% 2 \mathrm{Cwrdl} \% 3 \mathrm{~A} \% 20$ conorte> (consulta del 06 de mayo de 2021). Véase, a su vez, García Andrés (1999: I, 69-74).

4. Sobre el inicio de la campaña de reforma de la Reyes Católicos, véase García Oro (1980: 280290) y Omaechevarría (1972: 114-118). 
cuarto voto (aquel de clausura), la percepción de rentas y, adicionalmente, el curato de la parroquia anexa al Convento de Santa María de la Cruz por parte de las monjas (García Andrés 1999: I, 55-62). Este privilegio que tantos conflictos causara en la comunidad (Grańa Cid 2017) es el marco esencial en el que debemos entender los trece años de actividad predicadora de Juana donde, como párroco, realizaba un comentario bíblico marcado no solo por la festividad litúrgica del día, sino de forma más específica por los textos evangélicos que se leían durante la misa (Acosta-García, en preparación, 2023).

Para oír estos sermones se congregaba en la iglesia un público híbrido, laico y religioso, que asistía a auténticas representaciones visionarias. ${ }^{5}$ Estas se insertan en la tradición teatral del convento, que incluye los autos presentes de manera transversal en los diversos materiales "literarios" que de la casa religiosa se han conservado (Sanmartín Bastida 2018). Sus prédicas duraban hasta seis horas y se justificaban en lo que atañía a la autoridad no solo porque Juana fuese el párroco de la iglesia, sino también por el su carácter revelado de sus palabras: era "el Señor", es decir, Cristo, quien pronunciaba (parte de) las palabras de su boca. ${ }^{6}$ En este contexto de predicación, la presencia de composiciones líricas en la obra vinculada a Juana de la Cruz (principalmente, el Conhorte y el llamado Libro de la casa) ha sido puesta en evidencia por María Victoria Triviño, que habla sobre la actividad poética de la abadesa realizando una síntesis de estos aspectos en su obra. ${ }^{7}$ El texto de Trivińo es interesante por varios motivos pero, sobre todo, porque espiga seis de las composiciones que se encuentran insertas en algunos sermones del Conhorte (y que representan un conjunto disgregado por todo el libro, diverso del cancionero que enseguida trataré). En efecto, para un lector atento no es difícil intuir en algunos pasajes de los sermones composiciones líricas que, a pesar de que su misse en page se da en prosa en los dos manuscritos supervivientes, son fácilmente reconstituibles en estrofas y versos. La primera pista que nos indica que estamos ante una composición de este tipo suele ser la existencia de marcadores textuales que describen a personajes celestiales desarrollando una actividad musical en connivencia con la comunidad religiosa de Cubas que ento-

5. Estas sesiones se encuentran bien descritas en la primera hagiografía de Juana (véanse los ff. citados en la nota 2). Sobre la liturgia en el Convento de Santa María de la Cruz en Cubas de la Sagra en relación al Libro del Conhorte, publicaré proximamente un monográfico que también profundizará en el ausnto de la transcripción de los sermones visionarios de Juana y en su performance (Acosta-García, en preparación, 2022). En general, respecto al público de la lírica religiosa castellana habla Wardropper (1958: 101-103).

6. El debate sobre la predicación de las mujeres en la Iglesia es antiguo, para una discusión sobre la misma desde el punto de vista conventual, que pone su acento en la liturgia, véase Schlotheuber (2020), así como los materiales contenidos en Kienzle y Walker (1998). Para el discurso proféticovisionario como forma de prédica femenina en los conventos que asienta su autoridad en una instancia divina en contextos italianos muy similares a este, véase Zarri (2010). Véase, a su vez, Muessig (en prensa), que incluye a Juana en una nómina de predicadoras premodernas a nivel europeo.

7. Triviño (2004). 
na el oficio en la tierra, por lo que en muchas ocasiones las palabras que pronuncian y que se recogen como parte del sermón deben ser entendidas como un canto (Curto 2018). ${ }^{8}$ Por supuesto, esto forma parte del evidente carácter multimedia que revisten los sermones de Juana, de la relación con su público y, a su vez, de los vínculos que establecen aquellos no solo con la gestualidad, sino también con la música (Luengo Balbás 2016: 183-292).

Para ilustrar el tipo de lírica camuflada en la prosa del Conhorte, propongo ahora un ejemplo que Triviño no recoge en su estudio, que tampoco forma parte del cancionero que forma el núcleo de este artículo, pero que me servirá para retomar algunas cuestiones fundamentales relativas a la materialidad del manuscrito del Vaticano, desde el cual realizo directamente esta reconstrucción. Localizamos estos versos en el sermón dedicado a la Encarnación (García Andrés 1999: I, 231-258). A pesar de que, reitero, la mise en page original es en prosa, ofrezco aquí una estructura en verso bastante evidente, donde separo las estrofas y relleno las lagunas entre corchetes hasta donde me permite la comparación entre los códices y la deducción lógica. ${ }^{9}$ Juana está describiendo a viva voz una visión que transcurre en un contexto esponsal: Cristo (es decir, la voz parlante de Cristo a través del cuerpo de Juana) abraza a su madre, la virgen María, la besa y la loa con unas palabras que son un canto de amor: ${ }^{10}$

[Tú sola, mi a]miga, [tú sola m]e contentaste.

Tú so[la, mi a]mada, escogida entre millares.

Tú sola, mi rreyna, en quien yo rreyné e moré.

Tú sola, mi esposa, de[ quien y]o me pagu[é].

[Tú sola, mi] escogida, de q[uien yo me ...]é.

Tú sola, mi enamorada, con quien mucho me deleité.

8. Véanse los ejemplos que esta estudiosa aporta, verbigracia, en las pp. 96-97 y 101.

9. Esta posibilidad ya había sido bocetada por García Andrés (1999: I, 248), que también entendió estas líneas estróficamente, transcribiendo en verso los ocho que conserva el manuscrito de El Escorial, f. 21r. Véase mi propia edición, diferente a la del editor del Conhorte, en la nota siguiente. 10. El canto que reconstruyo como una sucesión de coplas paralelísticas en cuartetas se encuentra en el manuscrito del Vaticano, f. 13v, donde leemos (aquí también la separación de las estrofas y los versos es mía. Los criterios de edición son los mismos que describo abajo para editar el cancionero): "Tú sola mi amiga, / tú sola me contentaste. / Tú sola, mi amada, / escogida entre millares. // Tú sola, my rreyna, / en quien yo rreyné y moré. / Tú sola, la más santa, / que e hallado ni hallaré". 
Tú sola, mi paloma,

Con quien yo mucho folgué.

Tú sola, la más santa,

que e fallado ni fallaré.

Imaginando dentro de lo posible el contexto para-teatral en el que estas palabras pudieron pronunciarse queda medianamente claro que debían ser cantadas por Juana en un momento narrativamente marcado del sermón, regulando su voz para que Jesucristo las pronunciase a través de su boca, tal y como describen varios testigos de sus éxtasis. ${ }^{11}$ Esta suerte de transvestismo en la que Juana hace de medium, lo podremos verificar de una manera muy concreta en el breve cancionero que está en el centro de este artículo. Sin embargo, no quiero dejar pasar esta oportunidad de hacer una reflexión sobre los dos manuscritos del Conhorte.

La historia de la transmisión de los sermones de Juana está aún más por reinterpretarse que por escribirse. Como ya he dicho, García Andrés realizó en 1999 el enorme esfuerzo de proporcionar una edición completa del manuscrito de El Escorial, que incluía una solvente "Introducción" que explicaba el origen y los avatares del Conhorte, relacionados estos, sobre todo, con el proceso fallido de beatificación de Juana (García Andrés 1999, I, 13-68). En esta "Introducción" discutía las razones para editar solo el manuscrito de El Escorial frente a aquel del Vaticano, concluyendo tajantemente que el escurialense era "el primero y original que recogió los sermones de Juana de la Cruz" (García Andrés 1999: I, 73). A la espera del estudio que estoy realizando que reevaluará la función de ambos manuscritos como transmisores del texto (Acosta-García, en preparación, 2023), debemos al menos aceptar por ahora que los códices presentan variantes importantes que deben ser tenidas en cuenta para cualquier hermenéutica válida de los sermones. Estas han pasado inadvertidas para los estudiosos que, lógicamente, han trabajado en su inmensa mayoría con la edición de 1999. El caso concreto de la composición que transcribo arriba, por ejemplo, muestra que la necesidad de cotejo de ambas versiones es clara: además de que es básico para completar las lecturas del manuscrito del Vaticano (que, a pesar de haber sido restaurado poco después de la apertura de la causa de canonización en 1986, está plagado de lagunas por una afectación de la composición de la tinta en el papel), nos indica que en muchas ocasiones este presenta variantes, si aún no puedo afirmar que siempre más "correctas" sí, como en esta y otras muchas ocasiones, más completas que las del manuscrito de El Escorial. Y no solo porque esta versión parezca que amplíe y/o glose los textos: sin ir más lejos, en este caso, el manuscrito de El Escorial omite ocho versos (del siete al catorce en mi transcripción), que solo se encuentran en el manuscrito del Vaticano (aunque con lagunas) y que hasta ahora estaban inéditos.

11. Sobre los atributos viriles de Juana, presentes tanto en su hagiografía como en algunos relatos de su proceso de canozación, y su significación sociocultural, ha hablado Boon (2018). 
En todo caso, dejando aparte este problema filológico fundamental que, como digo, trataré en un estudio próximo en detalle, la existencia de esta canción en ambos códices, sumada a las otras que edita Trivińo y las que desvelaré junto a María Victoria Curto en un artículo también futuro, evidencia no solo la riqueza aún por explotar de un corpus lírico intercalado en el Conhorte, sino la importancia fundamental que estas piezas poseían como una parte de la experiencia performativa que las englobaba. ${ }^{12}$ Por supuesto, estas composiciones entroncan con la tradición juglaresca franciscana, cuyas manifestaciones primarias las instaurara el fundador de la orden y que fueron continuadas con innumerables variaciones por las generaciones de hermanos posteriores hasta cristalizar en la lauda. ${ }^{13}$ Este hecho no se hace explícito solo de manera "indirecta" en los textos que rescata Trivińo de la masa de los sermones visionarios de Juana sino también, precisamente, en un pequeño corpus que se encuentra en el manuscrito Vaticano y que es la justificación de estas páginas. El descubrimiento del grupo de composiciones al final del códice se debe de nuevo a la estudiosa clarisa, que anunció su inventio en las actas de 2004 que vengo citando, donde les dedica una subsección (Triviño 2004: 1260-1265). Allí, bajo la rúbrica "poemas del Conhorte-Vaticano", dice lo siguiente (Trivińo 2004: 1264):

Al final del manuscrito Vaticano del Conhorte hay un apéndice con tres poemas. Por estar recogidos en este lugar, se comprende que sus destinatarios eran todos los cristianos. Su anotación reza así: "Estas coplas susoescriptas / por boca de Dios son dichas". El primer poema canta el poder de Dios; el segundo la Encarnación; el tercero parece una versión popular de las Lamentaciones, recorriendo toda la vida del Señor desde la encarnación hasta la exaltación y la Eucaristía.

Posteriormente, la investigadora clarisa edita cuatro estrofas y el estribillo de una de las composiciones. Si bien el descubrimiento de Triviño reviste una importancia inmensa, en su comunicación se da una serie de problemas fundamentales que atańen a la difusión y estudio de estos textos: en primer lugar, su hallazgo no ha tenido el eco que se merece (ni siquiera en el grueso de los estudios específicos sobre Juana de la Cruz); en segundo, la edición que realiza es evidentemente incompleta y no aporta cierta información material ni contextual, claves ambas para el correcto entendimiento de los textos y, en tercero, la información que da sobre ese "apéndice" contiene errores. Por un lado, no son tres, sino cinco las canciones que nos encontramos al final del denominado manuscrito Vaticano, por lo que habría que revisar su descripción posterior del contenido de los poemas. Por otro, la "anotación" que Triviño da no es la inte-

12. La conexión entre predicación femenina, profetismo y canción ha sido puesta de relieve por Muessig (1998) y está siendo desarrollada por autoras como Wang (2020).

13. Para la significacion del canto, la música y la danza para el primer franciscanismo, véanse, por ejemplo, los ensayos contenidos en Loewen (2013). 
resante introducción que encabeza el corpus, sino la mitad de una de la última estrofa de la composición [II], como comentaré más adelante.

Este breve grupo de composiciones parece poseer una significación esencial que comprende ámbitos de estudio diversos, que va desde la Historia de la Literatura y pasa por la investigación de sobre la religiosidad europea, la literatura mística, los estudios de género o la lírica castellana premoderna. Además de proporcionar una edición solvente de las canciones, en este artículo intentaré responder, siquiera de una manera parcial, a las siguientes preguntas a través de un análisis y comentario iniciales, pero detallados de los textos a través de su función contextual: ¿Quién era el auditorio de Juana y cómo interactuaba con lo que ha sido llamado "teatro del trance" (Sanmartín Bastida 2012: 241-289)? 14 ¿Qué aportan estos versos los estudios sobre Juana de la Cruz y la puesta en escena de su predicación? ¿Qué suponen para nuestro conocimiento de la vida franciscana femenina intraconventual premoderna, no solo a nivel castellano, sino en un marco transnacional? Para ello proporcionaré en el siguiente punto información contextual sobre en anclaje histórico de estos textos y el manuscrito que los transmite. Posteriormente, en una segunda sección, realizaré una edición de las canciones para, en una tercera, realizar breves comentarios métricos y teológicos de cada una de ellas. En fin, a modo de conclusiones, se describen una serie de líneas de investigación abiertas.

\section{Contexto de un cancionero visionario}

En primer lugar, quizá convendría justificar la etiqueta de "cancionero" que utilizo en el título de este trabajo para referirme al grupo de composiciones que cierran el manuscrito Vaticano. Por supuesto, dada la cronología de Juana y su coincidencia con la época de la mayoría de los grandes cancioneros castellanos, soy consciente del posible equívoco al que puede llevar denominar así a un grupo tan breve de poemas, que quizá encajaría mejor con la denominación "cancionerillo". ${ }^{15}$ Sin embargo, frente a posturas más restrictivas para el uso del término como la de Dorothy Severin, yo me ciño aquí a definiciones más abiertas, como la de González Cuenca de "depósito de canciones" que, en el caso de las canciones vinculadas con la actividad profética de Juana reunidas por su comunidad, contrasta con las composiciones insertas en los sermones como la que acabo de transcribir. ${ }^{16}$ La razón principal para adoptar esta nomenclatura no

14. Sobre esta noción, véase, a su vez, Giles (1995 y 1996).

15. Agradezco a Vicenç Beltrán esta sugerencia que también constituye una línea de indagación futura.

16. Para ambas definiciones, véase la discusión de Roncero López (2004: 5-98) en la introducción a la miscelánea de Dutton, que refrenda la definición de Gónzalez Cuenca aportando dos añadidos que se cumplen en nuestro caso: "que se trate de un conjunto de poesías [...] que se hallen recogidas en soporte material, ya sea manuscrito e impreso" (18-19). 
reside simplemente en su historicidad en el cuatrocientos castellano (Roncero López 2004: 19), sino también en la certeza de que nos encontramos ante un material que en sus orígenes fue cantado, ya que en el mismo manuscrito vaticano el texto se refiere a estos textos como "cantares" (en una nota introductoria que enseguida analizaré) o "cantar" (como rúbrica de la composición [V]). En este sentido, estaríamos ante el cancionero de Juana de la Cruz, entendiendo por esa preposición que fue ella la que pronunció estos versos, aunque su autoridad, en el contexto profético en el que se dieron, proviniese de la gracia encarnada en la abadesa y su composición deba ser entendida en el ámbito comunitario. Por otro lado, las canciones fueron muy probablemente entonadas en momentos diversos y aquí se guardan en un conjunto consultable por lo que se compilan a la vez que se preservan para las mismas monjas, rasgo que comparte con un cancionero casi contemporáneo proveniente de un ámbito franciscano femenino muy similar (aunque de carácter evidentemente menos mistico), aquel musical de Astudillo (Cátedra 2005). ${ }^{17}$

En este caso son las hermanas de Juana las que lo recopilan y escriben en una nota que preside la colección lo siguiente: ${ }^{18}$

Síguensse unos cantares que ssegún parescía el mesmo Señor cantaua algunas vezes e ssu sierua rrespondía. E nosotras lo oýamos. Bien cuarenta perssonas e cincuenta fartas vezes estaríamos. E digo cincuenta porque contino héramos tantas cerca dellas. E otras vezes sse llegavan más de otras ciento e cincuenta.

Dejando los aspectos eminentemente materiales a un lado, la primera característica a comentar de este texto es la afirmación "E nosotras lo oýamos", pues es la frase que nos permite situar su transcripción en su contexto comunitario (indudablemente el femenino apunta a ello), que incluye a la vez una voluntad compiladora. Como se ha defendido en varias ocasiones a través de ciertos testimonios

17. Junto a una descripción del códice, Cátedra (2005: 174) aporta fecha de escritura aproximada de los primeros cuadernos de este cancionero, que sitúa "no más tarde de mediados del siglo xv". Por razones que se harán enseguida evidentes, he evitado la etiqueta "musical".

18. Véanse los criterios de edición en la siguiente sección. Esta nota aparece algo emborronada por una mancha de tinta diluida que impregna las frases y que las hace aún hoy difícilmente legibles. Seguramente, esta es la razón por la que en un momento indeterminado una mano moderna realiza en el margen izquierdo una transcripción de la misma, reproduciendo su contenido. Después de contactar con el "Laboratorio di Conservazione" del Archivio Apostolico Vaticano, puedo afirmar que con toda probabilidad que esta no se debe a una censura del documento, ni a la aplicación de reactivos para aumentar la legibilidad del texto, sino a la restauración a la que el documento fue sometido c. 1986. "[I]l degrado sarebbe dovuto all'azione combinata dell'inchiostro, che ha corroso il supporto, e di un tentativo di salvaguardia tramite foglio adesivo, applicato prima dell'intervento finale e complessivo. L'agente adesivo e l'operazione di rimozione del summenzionato foglio dovrebbero aver causato il maggior abbrunimento di quella specifica porzione di testo" (Marco Grilli, Segretario della Prefettura del Archivio Apostolico Vaticano, en comunicación personal del 28 de abril de 2021). Agradezco a Nigel Palmer su ayuda especializada para intentar aclarar este asunto. 
presentes en los sumarios del proceso de canonización de Juana, no solo su primera vita posee una autoría colectiva cierta, sino también la transcripción de los sermones del Conhorte tal y como los conocemos (Acosta-García 2021a: 3-5). Según Zarri (2011: xiii), esta es una característica de los monasterios observantes femeninos a partir del siglo XV y, en el caso de esta nota en concreto, no solo nos sirve para confirmarlo, sino que también nos ayuda a entender algunos rasgos determinados de la predicación de Juana, relativos al espacio y a la posible interacción que se produce con su público. Respecto a esto, lo primero que notamos es que el plural comunitario contiene una nota de presencialidad: la comunidad estaba allí durante la predicación, pero las hermanas no estaban solas. Junto a ellas o, mejor, de alguna manera compartiendo con ellas su papel de público existe un número cambiante de personas (cuarenta [...] cincuenta) que asisten a la prédica. Lo único que se puede afirmar con certeza sobre esta indeterminada audiencia es que, desde el punto de vista de la perspectiva narrativa, se desea dejar constancia tanto de su variedad (sin duda, "sse llegavan" habla de públicos cambiantes) como de su multitud, a lo que apunta el último cómputo (ciento e cincuenta).

Esta mixtura no solo de un público cortesano y poderoso del que ya teníamos noticias desde su primera hagiografía, sino quizá también de parroquianos $y$, con seguridad, de las recientemente enclaustradas monjas de la comunidad, me hace suponer que el lugar donde ocurría la predicación inspirada de Juana fuese tras las rejas del coro de la iglesia. ${ }^{19}$ Además, esta escena así planteada apoya las palabras de Graña Cid quien cree que, tras la reforma cisneriana de esta comunidad en particular, "no se dio la monacalización completa del monasterio, que mantuvo un estatus de relativa indefinición regular". ${ }^{20}$ Esta nota parece confirmar, pues, la porosidad de los muros del convento toledano a inicios del siglo Xvi, causada y reforzada por el papel que el Cardenal Cisneros adjudicó en la cura de almas de la parroquia directamente a Juana y sus hermanas. Pasaré ahora a proveer de una edición de las canciones, para desarrollar una serie de líneas interpretativas posteriormente.

19. Luengo Balbás y Atencia Requena (2019: f. 27v). Vale la pena repoducir el pasaje de Vida y fin donde se describen los incios de su predicación junto a un auditorio: "Oýanla frayles de algunas órdenes, predicadores e letrados, e abades e canónigos, e obispos e arçobispos, y el cardenal de España don fray Francisco Ximénez, de gloriosa memoria, e los ynquisidores de la Sagrada Ynquisiçión, jueçes della, e condes, e duques e marqueses, e cavalleros muy graçiosos, e señores e todos otros estados, assí de hombres como de mujeres, que este misterio vieron e oyeron, y estuvieron en él presentes. Veýan cómo estava esta bienabenturada bestida e tocada de religiosa como lo hera, y hechada sobre una cama de la manera que las religiosas la ponían, e sus braços puestos a manera de persona recogida, y el cuerpo como muerto y los ojos çerrados, y el gesto muy bien puesto e muy hermoso, resplandeçiente a manera de lleno e redondo. Esto tenía quando la graçia del Spíritu Sancto hablava con ella, que de su natural le tenía aguileño. / E quando esta graçia le dava el Señor, primero se elevava en el lugar que aquella graçia le tomava, e las monjas la tomavan en los brazos e la ponían sobre una cama. E de aý un poco de interbalo, veýan en ella señales que veýa al Señor".

20. Graña Cid (2004: 309-310). 


\title{
El texto de las canciones
}

\section{a) Criterios de edición}

En general se mantienen todas las características ortográficas de la fuente (ç, ss, rr, $h$ inicial aunque no sea etimológica, diferenciación $v / u$ ), con las siguientes excepciones: la $\int$ se normaliza a $s$, mientras que la $j$ vocal se transcribe $i$. He adaptado la acentuación a la ortografía moderna, he expandido todas las abreviaturas (que desarrollo en cursiva), he añadido puntuación moderna a las estrofas y regularizado, por tanto, el uso de las mayúsculas. Las vocales elididas en el manuscrito se marcan con apóstrofos. Las lagunas (muy comunes en el manuscrito) se identifican entre corchetes [...] y se restablece el texto entre ellos cuando la deducción lógica lo permite. Uso la misma convención para indicar la repetición completa de ciertos estribillos, que en el manuscrito solo se indica con su/s palabra/s de inicio. También entre corchetes se numeran las composiciones, tengan o no rúbrica en la fuente. Algunas lecciones dudosas se dan seguidas de (?).

\section{b) Edición}

Síguensse unos cantares que ssegún parescía el mesmo Señor cantaua algunas vezes e ssu sierua rrespondía. E nosotras lo oýamos. Bien cuarenta perssonas e cincuenta fartas vezes estaríamos. E digo cincuenta porque contino héramos tantas cerca d'ellas. E otras vezes sse llegavan más de otras ciento e cincuenta.

\author{
[I] \\ Ihesus \\ Yo me ssoi quien ${ }^{21}$ soy. \\ Yo me ssoi el Señor. \\ Dende las altas rriberas \\ mando las yglessias. \\ Yo me ssoi el Señor. \\ Dende los altos cielos \\ mando todos los pueblos. \\ Yo me ssoi el Señor. \\ Mando las yglessias \\ y aun a las planetas. \\ Yo me ssoi el Señor.
}

21. Palabra sobrescrita con otra tinta más clara que hace el texto casi ilegible, aunque cabe esta lectura. 
Mando todos los pueblos y avn a los elementos.

Yo me ssoi el Seńor.

Y aun a la[s planeta]s

en mi uirtud mudan (?) ellas.

Yo me ssoi el Señor.

$\mathrm{Y}$ avn a los elementos

en mi virtud an (?)ellos.

Yo me ssoi el Señor.

[II] Otras coplas

Dezidme, amigos, dezí,

ssi auéis manzilla de mý.

A vos digo, los cristianos, que yo amo a los humanos, pues todos ssois mis hermanos que vuestra carne vestí.

Dezidme [...]

Sabed que ssoi Ihesus Cristo y ssoi fijo de dios biuo y de la virgen nascido y en este mundo os serví.

Dezidme [...]

Yo ssoi el Dios prometido y en el mundo fui venido y no fuy bien conoscido de lo cual pena ssentí.

Dezidme [...]

Y ssi yo sentí gran pena

fue por la lástima [...ena] que pierden la uid[a ...e]na mas que no por la de mý.

Dezidme [...]

Yo ssoi el cruscificado que ssufrí muer[te de] grado por fazer noble mandado del padre de quien ssalí. 
Dezidme $[\ldots]$

Yo ssoi el que vos [...om]é et muy caros vos [...]omé, que por vos muerte tomé aunque no la merescí.

Dezidme [...]

Yo descendí a los infiernos, a lugar ssin rrefrigerio.

Desaté los captiuerios de los que allí llorar ui.

Dezidme [...]

Yo rressucité muy cierto y de mi passión sané presto sin físsico y ssin maestro ${ }^{22}$ y por ello vos redemí.

Dezidme [...]

Yo ssobí a los altos cielos ssin escalas ni agujeros con poderes muy eternos del padre y también de mý.

Dezidme[...]

Yo vengo en el ssacramento que me gusten ssoi contento pues que ssin enpedimiento por vos la muerte ssufrí.

Dezidme [...]

Y allí sso yo contenido, Dios y honbre todo misto, $y$ en forma de pan ssoy visto del pueblo que rredemý.

Dezidme [...]

22. El mismo Jesucristo aparece como físico en una de las visiones del Conhorte, véase García Andrés (1999: I, 249). 
Todos los que me gustades muy grandes bienes ganades que sse quitan v[uestros (?)] males porque yo lo quisse anssí.

Dezidme [...]

Y todos los que ssois bivos oýdme ssi avéis oýdos que por mi ssois rredemidos. Vosotros creeldo anssí.

Dezidme [...]

Yo de grado uos merqué porque fuéssedes benditos y biva ssangre pagué. Tengo bienes infinitos d'ellos muchos os daré ssi me sseruides a mý.

Dezidme [...]

Más passé yo en un pessar que vos en dozientos myll ${ }^{23}$ e aunque mucho os me queráis no fagáis, fijos, anssí.

Dezidme [...]

Estas coplas ssuso escritas por boca de Dios sson dichas y el ángel que las oyó las cantó y las dixo anssí.

Dezidme, amigos, dezí, [ssi auéis manzilla de mý.]

\section{[III]}

Ihesus

¡Ay, ay, pecadores, que no os enmendáis cuán mal lo miráis, quán mal lo miráis!

23. La doble ele final está ańadida a posteriori por otra mano. 
Descendí del cielo,
del cielo Inpirio.
Vine fasta el ssuelo
como peregrino.
Biví ssin abrigo
y no lo penssáis.
¡Cuán mal lo miráis,
cuán mal!

Ssin dexar de sser Dios, honbre verdadero vine $s[. .$.$] os.$

Como un cordero

biuí lastimero y no's acordáis.

¡Cuán mal lo miráis, cuán mal!

Una virgen pura quisse yo escoger grande en fermossura.

Mucho a mi querer

fízome plazer.

No la rremedáis.

¡Cuán mal lo miráis, cuán mal!

Por sser humyldossa

y de coraçón

alcançó tal gracia y meresció tal don. Sube ssu oración a do no penssáis. ¡Cuán mal lo miráis, ay, ay, pecadores ${ }^{124}$

Los ángeles todos fázenle omenage. Cada uno d'ellos sse le faze par. ¡O yngrato linage, el tie[...] que passáis! ¡Cuá[n mal lo] miras (sic)!

24. Este último verso fue añadido a posteriori por otra mano. 
¡Ay, ay, pecadores, que n'os enmendáis!

¡Cuán m[al lo] miráis, cuán mal lo miráis!

[IV] Otro villancico

Que non estay non

en las dinidades gloria, que non estay non

en las rriquezas la honrra.

Escogí yo unos amigos para fazer (?) conpañía. Cuando me tuvieron allá quitáronme ell alegría.

Que non estay non en las rriquezas la honrra, que non.

Escogí yo unos amigos para mí conssolación.

Cuando me tuvieron allá diéronme muy gran passión.

Que non estay non en el pressumir la honrra, que non.

Cuando me tuvieron allá quitáronme ell alegría fiziéronme tales llagas que me duelen oy en día.

Que non estay non en las rriquezas la honrra, que non.

Cuando me tuvieron allá diéronme muy gran passión, fiziéronme tales llagas que asta oy tengo el dolor.

Que non estay non en el pressumyr la honrra, que non. 
Fiziéronme tales llagas que me duelen oy en día de uer las gentes tan malas llenas de malicia y enbidia.

Que non estay non en las riquezas la honrra, que non.

Fiziéronme tales llagas que asta oy tengo el dolor de uer las gentes tan malas y tan llenas de pressunción.

Que non estay non en el pressumir la honrra, que non.

De uer las gentes tan malas llenas de malicia y enbidia que no myran a ssu Dios, ni toman la ssu dotrina.

Que non estay non en las rriquezas la honrra, que non.

De uer las gentes tan malas y tan llenas de pressunción que no miran a ssu Dios, a ssu Dios y ssu señor.

Que non estay non en el pressumir la honrra.

Que non estay non en las dinidades gloria. Que non estay non en las rriquezas la honrra

[V] [E] otro cantar

Con chicos y [gran]des y pequeños, con todos me deleyto yo.

Por las calles de my rreyno [yo veo sa]ntos ssin cuento. Con todos me deleyto yo, con chicos $[\ldots]$. 
Por las calles de mi rreynado yo veo santos ssin cabo.

Con todos me deleyto yo, con chicos $[. .$.$] .$

[Yo veo] santos ssin cuento, todos de muy claro gesto. Con todos me deleyto yo, con chicos [...].

Yo veo santos ssin cabo, todos de gesto muy claro. Con todos me deleyto yo, con chicos [...].

Todos de muy claro gesto y ellos fazen lo que yo quiero. Con todos me deleyto yo, con chicos [...].

Todos de gesto muy claro y ellos fazen mi mandado. Con todos me deleyto yo, con chicos.

Y ellos fazen lo que yo quiero, todos tendidos por ssuelo. Con todo me deleyto yo, con chicos [...].

Y ellos fazen mi mandado y los finojos fincando.

Con todos me deleyto yo, con chicos [...].

Todos tendidos por ssuelo yo les doy m[uy g] ran conssuelo.

Con todos me deleyto yo, con chicos [...].

Y los finojos fincando Yo les doy muy gran [conssuelo (?)].

Con todo me deleyto yo, con chicos [...].

Yo les doi muy gran conssuelo y como a fijos les doi besso (?). Con todos me deleyto yo, con chicos [...]. 
Yo les doi muy grandes [...]

Y como a fijos los abraço.

Con todo me deleyto yo.

Con chicos y grandes y pequeños,

con todo me deleyto yo.

Ihesus Cristo Mariafilius

Deo gracias

\section{Las canciones: comentario métrico-teológico ${ }^{25}$}

Abordar el comentario de las cinco canciones de Juana en un artículo como este es complicado por las limitaciones de profundidad que admiten unas páginas que también incluyen una edición. Como afirmé en la "Introducción", mi objeto principal aquí solo es proporcionar una primera edición fiable y fijar unas líneas contextuales que ayuden a un desarrollo futuro del conocimiento de estas canciones. Uno de los pasos fundamentales a posteriori consistiría, sin duda, en ponerlas en contacto con la tradición lírico-musical franciscana, sobre todo con aquella de las laude y su probable incidencia en Castilla. ${ }^{26}$ Por tanto, en los siguientes párrafos realizaré solamente un breve comentario de cada una de las composiciones editadas, que comenzará describiendo algunas cuestiones formales de las mismas y continuará con unas palabras sobre la teología implícita de los textos.

Para comenzar, debo confirmar que las cinco piezas que nos encontramos en el manuscrito del Vaticano poseen una estructura con estribillo y vuelta, es decir que todas son formas típicamente cantables. Entre estas debemos distinguir, según la forma de las rimas: por un lado, los dísticos con estribillo y, por el otro, las formas típicamente zejelescas, entre las que se incluyen en este corpus la canción, el villancico y el zéjel propiamente dicho (Beltrán 2002: 51). Centrándonos en la primera tipología, tenemos las que he numerado como [I] y [V] que componen, para la época supuesta de su transcripción, dos raros ejemplos de canción paralelística, tal y como, siguiendo la hipótesis de Menéndez Pidal, la etiqueta Beltrán (1998b: 124). Este último autor entiende que existe una tradición entre este tipo de estrofa y la estructura de la cantiga de amigo paralelística y con leixa-pren que presenta raros ejemplos en el siglo Xv (Beltrán 2009:

25. Agradezco a Vicenç Beltrán su ayuda con los aspectos formales de estas canciones. La base de los comentarios métricos siguientes provienen de comunicaciones personales entre el especialista y yo. 26. La bibliografía sobre las laudas y su cultor más famoso, Iacopone da Todi, es casi inabarcable. Para un panorama general del contexto castellano del siglo xv al que me refiero aquí, son imprescindibles las páginas de Cátedra (2005: 354-375, especialmente 355-356, que se centran en los laudarios en Castilla y 358-359, donde apunta a una posible trasmisión de esta forma cantada por parte de los jerónimos a inicios del siglo xv). 
186). ${ }^{27}$ Tal tradición posee una continuidad formal total con la cantiga de amigo en la composición [V], que es canónica en el uso del leixa-pren (es decir, la tercera estrofa comienza con el último verso de la primera y la cuarta con el último de la segunda), si bien en la [I] las reglas del mismo se muestran más flexibles. Respecto al cómputo silábico, [I] está compuesto por octosílabos bastante regulares (salvo la excepción de la tercera estrofa de la mudanza), mientras que [V] presenta una relativa regularidad octosilábica que alterna con cierto anisosilabismo. ${ }^{28}$ Además, [I] posee un estribillo cuyo primer verso, como puede observarse en mi edición, posee dificultades de lectura, pero podemos representar su esquema de rimas como $\mathrm{xx} / /$ aay; por su parte, [V] se puede esquematizar como xy//aayx[y], siempre teniendo en cuenta las respectivas características del leixa-pren a las que acabo de aludir.

Ambas canciones son lo que frecuentemente se conocía como "cosantes" desde que Romeu Figueras (1950) lo bautizara a través de una lectura equívoca de Amador de los Ríos (Asensio 1970: 184). ${ }^{29}$ Los ejemplos que de esta forma existen provienen esencialmente de la lírica tradicional y es muy difícil encontrarlos en los cancioneros cortesanos del siglo xv (Beltrán 2009: 186). ${ }^{30} \mathrm{De}$ modo contrario a lo que parecen apuntar algunas de las otras canciones que edito en estas páginas, estas dos no parecen ser el contrafactum de ninguna popular: al menos no he hallado rastro de ellas en los principales repertorios de lírica medieval de este tipo. ${ }^{31}$ Estamos, pues, ante la supervivencia explícitamente activa a inicios del siglo XVI de cantares paralelísticos en un contexto religioso con claros vínculos cortesanos, que se distinguen de otros cantarcillos devotos conservados al darse en el ámbito de la revelación. Si bien existen ejemplos posteriores en la mística hispánica clásica de canto popular a lo divino (en Teresa de

27. Sobre esta forma véanse, a su vez, Frenk (1970) y Baños Vallejo (1991-1992).

28. Hay algunos versos decasílabos (verbigracia, el primer verso de la segunda estrofa de la mudanza, que retoma el leixa-pren con la variación rreynado frente a rreyno) y varios eneasílabos repartidos por la composición (por ejemplo, el segundo verso de la quinta estrofa de la mudanza, que se retoma en el primero de la séptima, y el segundo verso de la mudanza duodécima).

29. Sobre el "cosante" y sus relaciones musicales, véase Romeu Figueras (1965: 178-186). Esta terminología la recogieron, ayudando a popularizarla, manuales importantes como el de Navarro Tomás (1991: 64-66), que la define como: "Composición lírica de pareados enlazados entre los cuales se repite un breve estribillo. Cada pareado recoge en parte el sentido del anterior repitiendo alguna de sus palabras y lo continúa con adición de algún nuevo concepto".

30. En efecto, en su n. 34, Beltrán (2009) señala los "escasos ejemplos" localizados por Baños Vallejo. El mismo Beltrán (1998b: 116 y 131) aporta algunos ejemplos más. Navarro Tomás (1991: 167), por su parte, nos dice: "Como forma esencialmente propia de la lírica popular, el cosante no halló acogida en las colecciones de poesía cortesana del siglo xv. Varios ejemplos del Cancionero Barbieri indican, sin embargo, la difusión de tal clase de canción por Castilla...”. Para la difusión de la forma más allá de Castilla, véase. Romeu Figueras (1954). Para un estado de la cuestión de la lírica popular castellana, véase Pedrosa (2016: 303-352), que específicamente habla sobre los cantares paralelísticos en 340-343.

31. Para los contrafacta hispánicos véase Wardropper (1958), en especial para los castellanos del siglo xv, con diversos ejemplos (1958: 135-149). Véase también Frenk (2006 [1988]). 
Jesús y Juan de la Cruz, sin ir más lejos), en este caso el contexto del canto extático es esencial para entender estas canciones en todo su valor. ${ }^{32}$

En lo que concierne al contenido, el de la canción [I] es, esencialmente, una declamación del poder absoluto del Señor, entendiendo por este siempre en estos textos la figura de Cristo, sobre su creación. El tratamiento que se da a esta parece estar menos relacionado con un beneplácito franciscano sobre la misma (como el que encontramos en el fundacional Cántico de las criaturas, para entendernos) que con la expresión del poder absoluto del dios encarnado sobre ella. En efecto, si ponemos estas palabras en el contexto de los materiales que nos han llegado del convento del que Juana fuera abadesa (y particularmente relacionados con su figura), seguramente esta exaltación puede ligarse a cierta vena apocalíptica cultivada por las hermanas (Boon 2019), que se refleja en al menos dos sermones del Conhorte y en el fragmento del Libro de la casa que cito a continuación (García Andrés 1999: II, 1357-1372 y 1405-1416). ${ }^{33}$ Este habla de las revelaciones que a Juana le hicieron ángeles y santos, desarrollando el tema de la omnipotencia presente en las estrofas que estoy comentando hacia el final de los tiempos (Curto 2018: f. 59v): “'Que por cierto si esto no se guarda, que me levantaré', dixo el Padre, 'y disiparé la gente y la destruiré y mandaré a los vientos y planetas, agua y tierra y sequedad y truenos y tempestades que los persigan y hieran de llagas y tormentos y temores y temblores, hambres y guerras y pestilencias"'. Aquí, el uso de un léxico común liga el paso del control absoluto sobre el universo creado de la canción paralelística a su uso como castigo de los pecadores en el sermón apocalíptico.

Por su parte, la composición numerada por mí [II] y rubricada en el manuscrito del Vaticano como "Otras coplas" es un zéjel típico, donde "Dezidme" indica la repetición completa del estribillo durante el canto (lo que, en mi edición, marco con puntos suspensivos entre corchetes). ${ }^{34}$ Los versos son octosilá-

32. Para un resumen de la historiografía literaria y su búsqueda reconstructiva de una lírica castellana tradicional, véase Beltrán (1998b). Para ejemplos de cantares populares en boca de "místicos", véase Frenk (2006 [1988], 106-107), que se apoya en Wardropper (1958: 151-208, especialmente para los casos de Teresa y Juan, 159-180).

33. Estos dos sermones del Conhorte se rubrican en el manuscrito del Vaticano: "E Otra vez fablando el Señor sobre la venida del Antecristo..." (ff. 669v-679r) y "E otra vez fablando el espíritu del Señor rreprehendiendo a todo el humanal linage de ssus maldades e vicios e pecados e deleytes dixo..." (ff. 712v-718r), respectivamente. Por otro lado, cito por la edición en línea del denominado Libro de la casa (Curto 2018), realizada sobre el manuscrito de la Biblioteca Nacional de España, MSS/9661.

34. Frenk (2006 [1973]: 448-461) define esta forma como "estribillo inicial seguido de una o varias estrofas de tres versos monorrimos (mudanza) más un verso que rima con el estribillo (vuelta): AA bbba (AA) cca (AA)...”. Incluye ejemplos de composiciones religiosas en Frenk (2006 [1973]: $457-$ 458). Sobre el zéjel en la lírica tradicional hispánica la literatura es, lógicamente, considerable. (véase, por ejemplo, las reflexiones sobre el zéjel y la forma zejelesca en Morrás 1988-1989 y 1997). Por proponer ejemplos de zéjeles encabezados por dísticos monorrimos en el contexto del Cancionero de palacio, ver las composiciones recogidas por Dutton (1991: SA7-71, SA7-163, SA7-164, SA7-171, SA7-332, SA7-335 y SA7-353). 
bicos de una gran regularidad. Su esquema de rimas es $\mathrm{xx} / / \mathrm{aaax} / \mathrm{x}[\mathrm{x}]$, salvo las estrofas decimocuarta (que tiene cinco versos más verso de vuelta, que riman ababax $/ \mathrm{x}[\mathrm{x}]$ ) y decimosexta, que contiene el siguiente texto: "Estas coplas ssuso escritas / por boca de Dios sson dichas / y el ángel que las oyó / las cantó y las dixo anssí", rimando aabx/x $[\mathrm{x}] .{ }^{35}$ En la exigua documentación conservada proveniente del convento de Santa María de la Cruz, ${ }^{36}$ se puede confirmar que el zéjel era una forma estrófica de uso común, relacionada con los cantares de Juana e integrados en la liturgia colectiva, pues existe otro como este en un cantar largo del denominado Libro de la casa. ${ }^{37}$ Es esta una composición similar que nos podría ayudar a reconstruir la puesta en escena del zéjel del cancionero, porque añade más información contextual al tipo de canto. ${ }^{38} \mathrm{Al}$ inicio de la transcripción de aquel se lee (Curto 2018: f. 8r): "Estas palabras son un coloquio de nuestra madre santa Juana que tuvo con Nuestro Señor, y respuesta suya. Cántanse el día de la Cruz de mayo, que fue quando murió". Y posteriormente se da el estribillo junto a treinta y dos estrofas que siguen esta forma. Reproduzco aquí las del estribillo y la primera mudanza:

[Esposa] - Esposo, ¿`i avéis oýdo

quién me robó mi sentido?

[Esposo] - Esposa mía, en verdad no vos devéis maravillar, que mi dulçura es tal d'esto se havía recrecido.

Como podemos observar, sagazmente la editora del texto ha incluido entre corchetes la indicación de la persona que canta esa parte. En efecto, en los discursos que Juana ponía en escena ella debía adaptar su voz dependiendo de quien pronunciara las palabras. De hecho, la descripción de las voces de la nota inicial del corpus vaticano (“... ssegún parescía el mesmo Señor cantaua algunas vezes et ssu sierua rrespondía”) debe entenderse también de esta forma: la misma

35. Como ya expliqué arriba, Triviño (2004) había transcrito este texto, pero de forma parcial y considerándolo una "anotación".

36. Como nos informa la ficha del convento en PARES (<http://pares.mcu.es/ParesBusquedas20/catalogo/autoridad/7165>, consulta del 9 de mayo de 2021), este "[s]ufrirá las consecuencias de los avatares históricos y políticos del país, como, invasión de las tropas francesas, desamortización de Mendizábal o su destrucción en la Guerra Civil, siendo destruidos, no sólo su fábrica, sino también su biblioteca y su archivo". Actualmente el Archivo Histórico Nacional de Madrid (<http://pares.mcu.es/ParesBusquedas20/catalogo/description/1675364>, consulta del 9 de mayo de 2021) solo conserva unidades de los siglos XVII al XIX.

37. Esta será una de las composiciones que estudiaré con María Victoria Curto en el artículo anunciado en estas páginas sobre el resto de canciones relacionadas con Juana.

38. Esta composición ha sido estudiada en el contexto de la lírica espiritual hispánica por Cortés Timoner (2005). 
Juana cantaba con la voz masculina del Señor las mudanzas y rrespondía con su propia voz en el estribillo. En el caso de [II], por ejemplo, Juana cantaría con su voz "Dezidme amigos, dezí, / ssi aueis manzilla de mý" al emprender el canto y después de cada mudanza; mientras que la voz de Cristo se encargaría de cantar estas. Esta alternancia de voces no debía ocurrir en [I] que, como podemos observar en mi edición está encabezado por ihs (=Ihesus), lo que con toda probabilidad es una indicación de que la totalidad de este poema lo cantaba el "Señor", sin cambio de voces. Esto encaja perfectamente tanto con la primera persona que articula el canto, como con el tema del mismo que, repito, exalta y proclama su omnipotencia sobre el universo. La misma invariabilidad de voces existe en [III], encabezada también por "Ihesus" y también escrito en primera persona.

Así, en el caso del zéjel del Libro de la casa, estamos ante una evolución en la tradición de uso del texto: el original sería su declamación extática primaria por parte de Juana (lo que coincidiría con las canciones vaticanas que estamos analizando) que tras su muerte se utilizaría colectivamente en la liturgia, cuando sus hermanas siguieron cantando estas coplas para conmemorar ciertos hechos de la vida de su abadesa el día de la invención de la Santa Cruz. ${ }^{39}$ Es remarcable la traslación de un cantar probablemente pronunciado en un escenario visionario a la tradición litúrgica del convento, práctica que confirma el siguiente fragmento del Libro de la casa que hace referencia no solo a esta canción, sino al proceso de transcripción, que pasa por una mediación autoritaria sobrenatural (el ángel manda a Juana) y terrenal (la abadesa manda a su comunidad) (Curto 2018: f. 17r): “... Y entonces el Señor la respondió a ella en metro. Nuestra madre santa Juana la hizo escribir, que ansí se lo dijo el santo ángel lo hiziere. Y en este modo de responder el Señor en metro a las monjas ubo mucho”.

A nivel teológico, vemos que las quince mudanzas hacen un repaso a una serie de temas cristológicos fundamentales, hecho que a la hora de ponerlas en acto debía tener gran potencia escénica, al identificar el público a la primera persona que las entonaba con el mismo redentor. Sin duda, estas líneas están impregnadas de las formas de devoción medievales, intensificadas por las prácticas derivadas de un franciscanismo penitencial que sobrevivió en la comunidad de Juana y que está codificado tanto en su primera hagiografía como en ciertos pasajes del Libro de la casa (Acosta-García 2021a: 8-15). Un listado de los temas que recorren la canción sería: la encarnación y sus razones (estrofas primera y segunda); el adviento (tercera y cuarta); la redención (quinta, sexta); el descenso

39. Como leemos en otro fragmento del Libro de la casa: "El día de la Cruz de mayo nació nuestra madre santa Juana de la Cruz y tomó el hábito y murió; y en este día es costumbre en esta santa casa, en acabando de comer, yr a dar gracias adonde está su santo cuerpo, y allí dizen una corona de himnos y antífonas de las letras de su nombre. Y a la tarde cantan las coplas que dizen 'Esposo, ¿si avéis oýdo quién me robó mi sentido?', las quales están escritas al principio d'este libro, y leen allí su tránsito, y antes le solían dezir vísperas de virgen delante del arco donde está" (Curto 2018: f. 38r). 
de Cristo a los infiernos (séptima); la resurrección (octava); la ascensión (novena); la transubstanciación (décima, undécima); la comunión (duodécima); de nuevo, la redención, añadiéndole promesas de salvación (décimotercera, decimocuarta y decimoquinta). Como se comprueba aquí, tras este cantar existe un andamiaje narrativo que construye una teología de la salvación muy determinada, relacionada en último término con la presencia real de Cristo en la eucaristía y la posibilidad para el creyente de recibirla. Este se monta sobre un imaginario codificado en la devoción de la época y los ciclos narrativos derivados de una piedad no solo, pero sí típicamente franciscana, que intensifica con la circulación de obras como las Meditationes vitae Christi en la Península Ibérica (Cátedra 2005: 569-572). Además, denotan un uso muy concreto de las lecturas evangélicas, por lo que habría que estudiarlas en sus conexiones con la liturgia del convento.

Este tipo de imaginario que busca la compassio precisamente a través de la intensificación de los detalles más humanos de los evangelios y, sobre todo, de aquellos relativos a los episodios de la pasión está presente en otra de las composiciones del cancionero, la [IV]. En esta, vuelve Cristo a tomar la palabra para cantarnos su pasión, centrándose en dos puntos: los agentes de la misma ("unos amigos") y el sufrimiento que le causan en un lugar determinado ("allá"). A pesar de que tampoco aquí he podido localizar el posible poema de base, por su estribillo centrado en preocupaciones típicamente mundanas (dinidades, rrique$z a$, gloria, honrra) y cierta indeterminación en sus términos (amigos para referirse a los humanos que lo traicionaron y allá para hablar del Calvario, por ejemplo) este poema en particular parece un típico contrafactum cuyos versos originales no he sido capaz de encontrar en los repertorios al uso. Los elementos que permiten orientar su sentido hacia el sufrimiento de la passión son palabras de un ámbito más físico que aparecen después, como llagas y dolor (mudanzas de dos a cuatro) que, finalmente, acaba en una reprensión moral reiterada (mudanzas de cinco a ocho).

Centrándonos ahora en el cantar sin rúbrica que he numerado como [III], podemos observar que posee una forma estrófica que cabe identificar con la de la canción cortés, aunque despojada de la retórica de tipo cancioneril. ${ }^{40}$ El verso que utiliza es el "adónico sencillo", tempranamente descrito por Nebrija y estudiado en tiempos recientes por Proia, con un estribillo que utiliza seguidilla en su forma canónica. ${ }^{41} \mathrm{Su}$ esquema de rimas es xyyy //abab/byyy, con algunos versos de rima suelta. ${ }^{42} \mathrm{Si}$ tenemos en cuenta la rúbrica del cantar posterior en lo relativo a su

40. El mejor estudio de conjunto sobre el género es Tomassetti (2008). Véase, a su vez, la síntesis que realiza en Tomassetti (2016).

41. Sobre la canción cortés, véase Beltrán (1998a). En general, sobre el uso del hexasílabo, véase Navarro Tomás (1991: 77-78, 128 y 230-231). En particular, sobre el adónico sencillo, véase Proia (2016: 479-488, especialmente 482-488). Sobre la seguidilla, véase Frenk (2006 [1965]).

42. En dos ocasiones: en la cuarta mudanza, verso tercero y en la quinta mudanza, verso cuarto. 
percepción estrófica [IV] (“ Otro villancico”) parece lógico considerar que la/s transcriptora/s consideraba/n esta pieza como villancico, a pesar de que no cumpla con la regla definitoria enunciada por Juan del Encina (Obras completas, I, 25-26) para el mismo. ${ }^{43}$ La razón para esta identificación debe ser consecuencia histórica de la variabilidad, maleabilidad y no fijabilidad que Sánchez Romeralo asigna en varios pasajes de su obra al villancico. ${ }^{44}$ Tanto en lo concerniente al cómputo silábico como en lo relativo a las rimas, esta composición es muy irregular: su estructura podría estar basada en un esquema xyxy//abab/xyx, que en casi toda la composición se formaliza abcb/xyx y que solo se cumple de manera regular en tres (tercera, quinta y séptima) de las siete mudanzas.

Centrándonos en el contenido, puedo afirmar que [III] está emparentado con [II] en el sentido de que es Cristo en primera persona quien desarrolla una teología de la salvación determinada. En este caso, las seis estrofas que componen el poema se organizan dibujando una parábola que desciende (estrofa uno), toca tierra (estrofas dos y tres) y vuelve a ascender (estrofas cuatro y cinco). Así, en la primera mudanza se narra la bajada de la divinidad a la tierra desde el Inpirio (esto es, el Empíreo, el no-lugar donde según la tradición medieval habitan Dios y su corte celeste), pasa por la encarnación en la estrofa dos (desde la perspectiva de la humildad y el sacrificio: Cristo se figura a sí mismo como peregrino y cordero) para, en la estrofa tres, centrarse en la virgen María. Desde mi perspectiva, este giro es la verdadera justificación de la entera canción, pues supone una exaltación de la misma como receptáculo del Hijo. María recibe la gracia en la estrofa cuarta donde se la presenta en ascenso ("Sube su oración...”), llegando al culmen en la quinta, en el Empíreo de nuevo, donde los ángeles "fázenle omenage", en clara alusión a su asunción.

Por último, la canción [V], si tenemos en cuenta el estribillo (probablemente también un contrafactum, por cuestiones similares a las aducidas arriba para [IV]), abre las puertas al imaginario de la ciudad celeste, típica del mundo visionario de Juana. Como se viene estudiando desde hace varios años, los sermones de la abadesa franciscana suponen la interconexión de un reino celestial con el

43. Recordemos que la regla que del Encina enuncia es que un estribillo de tres versos corresponde a un villancico, mientras que aquel de cuatro o cinco versos lo haría con una canción. Sobre la historia del villancico y sus aspectos técnicos, véase Sánchez Romeralo (1969: 34-54). Este autor dice en su p. 40 que la consagración del villancico se da "a fines del siglo Xv y comienzos del xvı", lo que coincidiría con la cronología del cancionero que estoy manejando.

44. Sánchez Romeralo (1969: 128-129 y 143-144, respectivamente): “... el villancico se distingue por su variabilidad formal... la forma se nos presenta como dotada de elasticidad, de una maleable flexibilidad”; “... el villancico no es una forma poética (como lo son la copla, la seguidilla moderna, el soneto o la octava real), ni es un contenido poético determinado por una forma poética que lo preconfigura. El villancico es un decir poético, cuya forma no solamente no es fija, pero muchas veces ni siquiera es fijable". Por considerar un contexto religioso posterior pero similar en sus afanes devotos, Navarro Tomás (1991: 236) habla sobre la variedad formal de los villancicos atribuidos a Teresa de Jesús. 
semi-terrenal del convento a través de la celebración litúrgica (Curto 2021: 96102). Con un precedente claro en el Liber specialis gratiae de Mechthild von Hackeborn (Acosta-García, en preparación, 2023), los sermones del Conhorte despliegan un reino al modo de la Jerusalén celeste en el que los santos, los ángeles y los bienaventurados tañen instrumentos y cantan celebrando las fiestas del calendario litúrgico y haciendo partícipe a la comunidad del mismo. Este es el paisaje que nos propone [V], donde Cristo pasea "[p]or las calles de [su] rreyno" y los habitantes del mismo se le rinden como súdbitos. Otra imagen de la omnipotencia de Cristo redentor en el convento de Santa María de la Cruz.

\section{Notas conclusivas}

La edición de estas cinco piezas de Juana de la Cruz (seis, si contamos "Tú sola, mi amiga") es un primer paso para desenterrar el tesoro lírico que se encuentra en sus sermones e, incluso, en su primera hagiografía. El valor de este conjunto deberá ser calibrado en un futuro junto al corpus extraído del manuscrito del Vaticano que presento aquí y, sobre todo, a través de una comparación con la poesía religiosa de la época, no solo a nivel castellano, sino también europeo. Por ahora, puedo afirmar que el valor del cancionero vaticano de Juana de la Cruz no reside solo en su cristalina vinculación con la abadesa, sino en que la información contextual que poseemos nos permite entender algunos rasgos de su interpretación. A pesar de que es improbable que alguna vez recuperemos la melodía o una instrumentación posible con la que se cantaban estos textos, sí que la anotación inicial y algunos elementos textuales nos proporcionan rasgos descriptivos relacionados con el cambio de voces, el uso del estribillo, el espacio en el que probablemente se oían y el público de los mismos. Esto nos habla de una porosidad real del convento reformado de Santa María de la Cruz en Cubas de la Sagra, y de una relativización en la aplicación del cuarto voto en el mismo.

Estos horizontes abiertos presentan, de hecho, un terreno aún lleno de interrogantes que solo una investigación en profundidad sobre la lírica religiosa castellana de la época, en general, y de estas composiciones en ese contexto, en particular, podría resolver. Por ejemplo, una pregunta que requiere respuesta urgente es la relación de estas piezas con los sermones transcritos en el Conhorte. Su posición tras los setenta y dos sermones del manuscrito del Vaticano unida a su carácter visionario, a las otras canciones insertas en grueso del texto y a los datos que sobre su interpretación poseemos, parece apuntar a una relación significativa entre unas y otros. En este sentido, solo en un futuro próximo podremos aclarar si el canto se daba al final de algunos sermones (cosa que encajaría con ciertas prácticas documentadas para otros predicadores franciscanos) o si fueron extraídos de estos. Por otro lado, otra pregunta abierta es la relación de estas piezas y la liturgia del convento. En uno de los casos pudimos comprobar cómo una de las composiciones recogidas en el Libro de la casa nacía en ámbito 
extático y se convertía generaciones más tarde en parte de la tradición colectiva, siendo cantada en una fecha muy determinada en la que se conmemoraba la toma de hábito y la muerte de la abadesa. La puesta en común de los materiales lírico-litúrgicos que proveen El libro de la casa, el Conhorte y Vida y fin, primera hagiografía de Juana, pueden ayudarnos a entender la vida intramuros de un convento franciscano femenino tan atractivo (por su fama durante el reinado de los Reyes Católicos y los lazos de poder establecidos con la corte) como este. 


\section{Bibliografía}

Acosta-García, Pablo, "Radical Succession: Hagiography, Reform, and Franciscan Identity in the Convent of the Abbess Juana de la Cruz (1481-1534)", Religions, XII (2021a), en línea, <https://doi.org/10.3390/rel12030223>.

-, "'En viva sangre bañadas': Caterina da Siena y las vidas de María de Ajofrín, Juana de la Cruz, María de Santo Domingo y otras santas vivas castellanas", Archivio Italiano per la Storia della Pietà, XXXIII (2021b), pp. 143-172, en línea, <doi: 10.5281/zenodo.4580499>.

-, Liturgy and Revelation in the Book of the Conhorte by the Abbess Juana de la Cruz (1481-1534), Leiden, Brill, en preparación [2023].

Asensio, Eugenio, Poesía y realidad en el cancionero peninsular de la Edad Media. Segunda edición aumentada, Madrid, Gredos, 1970.

Baños VAllejo, Fernando Juan, "La más antigua lírica popular hispánica: otra tipología", Archivum: Revista de la Facultad de Filosofía y Letras, XLI-XLII (1991-1992), pp. 33-64.

Beltrán, Vicenç, El amor en el otoño de la Edad Media, Barcelona, PPU, 1998a.

-, "Poesía tradicional: Ecdótica e historia literaria", en Lírica popular/Lírica tradicional: Lecciones en homenaje a Don Emilio García Gómez, ed. Pedro M. Piñero Ramírez, Sevilla, Universidad de Sevilla-Fundación Machado, 1998b, pp. 113-135.

—, "Las formas con estribillo en la lírica oral del medievo", Anuario musical, núm. 57 (2002), pp. 39-57.

-, "Tradición, creación y contexto en la poesía oral antigua. Las tres morillas y la maurofilia temprana", Critica del testo, XII, 2-3 (2009), pp. 175-215.

Boon, Jessica A., "At the Limits of (Trans) Gender: Jesus, Mary, and the Angels in the Visionary Sermons of Juana de la Cruz (1481-1534)", Journal of Medieval and Early Modern Studies, XLVIII (2018), pp. 261-300.

-, "The Marian Apocalyptic of a Visionary Preacher: The Conorte of Juana de la Cruz, 1481-1534", en The End of the World in Medieval Thought and Spirituality, ed. Eric Knibbs, Jessica A. Boon y Erica Gelser, Londres, Palgrave McMillan, 2019, pp. 41-67.

CÁtedra, Pedro, Liturgia, poesía y teatro en la Edad Media. Estudios sobre prácticas culturales y literarias, Madrid, Gredos, 2005.

Cortés Timoner, María del Mar, "La mística nupcial en Sor Juana de la Cruz y San Juan de la Cruz", en Actes del X Congrés Internacional de l'Associació Hispànica de Literatura Medieval, coord. Rafael Alemany, Josep Lluís Martos y Josep Miquel Manzanaro, Alicante, Institut Interuniversitari de Filologia Valenciana, 2005, II, pp. 611-623.

Curto, María Victoria (ed.), "Libro de la Casa y Monasterio de Nuestra Señora de la Cruz", en Catálogo de santas vivas, 2018, en línea, <http://catalogodesantasvivas.visionarias.es/index.php/Juana_de_la_Cruz> [consulta del 8 de septiembre de 2020]. 
—, "Juana de la Cruz y la música en la mística castellana bajomedieval", Archivio Italiano per la Storia della Pietà, XXXIII (2021), pp. 87-118.

DutTon, Brian, El cancionero del siglo XV, c. 1360-1520, Salamanca, Universidad de Salamanca, 1991, IV.

Encina, Juan del, Obras completas, ed. Ana María Rambaldo, Madrid, EspasaCalpe, 1978, 4 vols.

Frenk, Margit, "Historia de una forma poética popular", en Carlos H. Magis (coord.), Actas del Tercer Congreso Internacional de Hispanistas, Ciudad de México, El Colegio de México, 1970, pp. 371-377.

-, "Lírica tradicional a lo divino", en Poesía popular hispánica. 44 estudios, Ciudad de México, FCE, 2006 [1973], pp. 448-461.

—, "Lírica tradicional a lo divino", en Poesía popular hispánica. 44 estudios, Ciudad de México, FCE, 2006 [1988], pp. 97-108.

—, "De la seguidilla antigua a la moderna", en Poesía popular hispánica. 44 estudios, Ciudad de México, FCE, 2006 [1965], pp. 485-496.

García Andrés, Inocente (ed.), El Conhorte: Sermones de una Mujer. La Santa Juana (1481-1534), Madrid, Fundación Universitaria Española-Universidad Pontificia de Salamanca, 1999, 2 vols.

García Oro, José, Cisneros y la reforma del clero español en tiempo de los Reyes Católicos, Madrid, CSIC, 1971.

—, "Conventualismo y observancia. La reforma de las órdenes religiosas en los siglos xv y xvı", en Ricardo García-Villoslada (ed.), Historia de la Iglesia en España, Madrid, La Editorial Católica, 1980, III, 1, pp. 211-350.

Giles, Mary E., "Holy Theatre/Ecstatic Theatre", en Anne Clark Barlett (ed.), Vox Mystica: Essays on Medieval Mysticism in Honor of Professor Valerie M. Lagorio, Cambridge, Boydell \& Brewer, 1995, pp. 117-128.

-, "The Discourse of Ecstasy: Late Medieval Spanish Women and Their Texts", en Jane Chance (ed.), Gender and Text in the Later Middle Ages, Gainesville, University Press of Florida, 1996, pp. 306-330.

Graña Cid, María del Mar, "El cuerpo femenino y la dignidad sacerdotal de las mujeres. Claves de autoconciencia feminista en la experiencia mística de Juana de la Cruz (1481-1534)", en Secundino Castro Sánchez, Fernando Millán Romeral y Pedro Rodríguez (eds.), Umbra, Imago, Veritas. Homenaje a los profesores Manuel Gesteira, Eusebio Gil y Antonio Vargas Machuca, Madrid, Universidad Pontificia de Comillas, 2004, pp. 305-336.

—, "Las profetisas ante el poder eclesiástico: denuncia y modelo místico de iglesia (Juana de la Cruz, siglo xvI)", en João Luís Fontes, Maria Filomena Andrade y Tiago Pires Marques (eds.), Género e interioridade na vida religiosa. Conceitos, contextos e práticas, Lisboa, Centro de estudios de História Religiosa-Universidade Católica Portuguesa, 2017, pp. 15-44.

Kienzle, Beverly Mayne, y Pamela J. Walker (eds.), Women Preachers and Prophets through Two Millennia of Christianity, Berkeley, University of California Press, 1998. 
Loewen, Peter (ed.), Music in Early Franciscan Thought, Leiden, Brill, 2013.

Luengo Balbás, María, Juana de la Cruz: vida y obra de una visionaria del siglo XVI, tesis doctoral, Madrid, Universidad Complutense, 2016.

—, y Fructuoso Atencia Requena (eds.), "Vida y fin de la bienaventurada virgen sancta Juana de la Cruz, monja que fue professa de quatro botos en la orden del señor sant Francisco, en la qual vivió perfeta y sanctamente", en Catálogo de santas vivas, 2019, en línea, <http://catalogodesantasvivas.visionarias.es/ index.php/Juana_de_la_Cruz> [consulta del 8 de septiembre de 2020].

Morrás, María, "Zéjeles o formas zejelescas? Observaciones para el estudio de un problema de historia literaria”, La Corónica, XVII, 1 (1988-1989), pp. 52-75.

-, "Fortuna de las formas zejelescas en la poesía castellana", Atalaya. Revue Française d'Études Médiévales Hispaniques, núm. 8 (1997), pp. 113-134.

Muessig, Carolyn, "Prophecy and Song Teaching and Preaching by Medieval Women", en Beverly Mayne Kienzle y Pamela J. Walker (eds.), Women Preachers and Prophets through Two Millennia of Christianity, Londres, University of California Press, 1998, pp. 146-158.

—, "Women as Performers of the Bible: Female Preaching in Premodern Europe", en Carla Bino y Corinna Ricasoli (eds.), Performing the Bible, Leiden, Brill, en prensa.

Muñoz Fernández, Ángela, "Iberian Women in Religion and Policies of Discipline Dissent in the Archbishopric of Toledo in the 15th to Early 16th centuries: The Heaven of Juana de la Cruz", en Fabrizio Titone (ed.), Strategies of Non-Confrontational Protest in Europe from the Twelfth to the Early Sixteenth Century, Roma, Viella, 2016, pp. 195-217.

Navarro Tomás, Tomás, Métrica española, Barcelona, Labor, 1991.

Omaechevarría, Ignacio, Las clarisas a través de los siglos, Madrid, Cisneros, 1972.

Pedrosa, José Manuel "Poesía castellana tradicional”, en Fernando Gómez Redondo (ed. en colaboración con Carlos Alvar, Vicenç Beltrán y Elena González-Blanco García), Historia de la métrica castellana, San Millán de la Cogolla, CILENGUA, 2016, pp. 303-352.

Proia, Isabella, "El hexasílabo y el adónico sencillo", en Fernando Gómez Redondo (ed. en colaboración con Carlos Alvar, Vicenç Beltrán y Elena González-Blanco García), Historia de la métrica castellana, San Millán de la Cogolla, CILENGUA, 2016, pp. 479-488.

Romeu Figueras, José, "El cosante en la lírica de los cancioneros musicales españoles de los siglos xv y xvı", Anuario Musical, núm. 5 (1950), pp. 15-61.

—, "El cantar paralelístico en Cataluña. Sus relaciones con el de Galicia y Portugal y el de Castilla", Anuario Musical, núm. 9 (1954), pp. 3-55.

- La música en la Corte de los Reyes Católicos. Cancionero musical de palacio (siglos XV-XVI), Madrid, CSIC-Instituto Español de Musicología, 1965, 2 vols. Roncero López, Victoriano, "Introducción”, en Brian Dutton y Victoriano Roncero López (eds.), La poesía cancioneril del siglo XV. Antología y estudio, Madrid-Fráncfort del Meno, Iberoamericana-Vervuert, 2004, pp. 5-98. 
Sánchez Romeralo, Antonio, El villancico (Estudios sobre la lírica popular en los siglos XV Y XVI), Madrid, Gredos, 1969.

Sanmartín Bastida, Rebeca, La representación de las misticas. Sor María de Santo Domingo en su contexto europeo, Santander, Real Sociedad Menéndez Pelayo, 2012.

—, "La puesta en escena de la historia sagrada a comienzos del siglo xvi: La batalla de los ángeles en la dramaturgia visionaria de Juana de la Cruz", Renassanceforum, XIII (2018), pp. 185-210.

Schlotheuber, Eva, "Doctrina privata und doctrina publica. Überlegungen zu den mittelalterlichen Frauenklöstern als Wissens- und Bildungsraum”, en Mirko Breitenstein y Gert Melville (eds.), Die Wirkmacht klösterlichen Lebens. Modelle-Ordnungen-Kompetenzen-Konzepte, Regensburg, SchnellSteiner, 2020, pp. 31-48.

Surtz, Ronald E., The Guitar of God. Gender, Power, and Authoritity in the Visionary World of Mother Juana de la Cruz (1481-1534), Filadelfia, University of Pennsylvania Press, 1990.

-, Writing Women in Late Medieval and Early Modern Spain: The Mothers of Saint Teresa of Avila, Filadelfia, University of Pennsylvania Press, 1995.

Tomassetti, Isabella, Mil cosas tiene el amor. El villancico cortés entre la Edad Media y el Renacimiento, Kassel, Reichenberger, 2008.

—, "El villancico", en Fernando Gómez Redondo (ed. en colaboración con Carlos Alvar, Vicenç Beltrán y Elena González-Blanco García), Historia de la métrica castellana, San Millán de la Cogolla, CILENGUA, 2016, pp. 541-581.

Triviño, María Victoria, "El arte al servicio de la predicación. 'La Santa Juana' (1481-1534). Franciscana de la TOR”, en Francisco Javier Campos y Fernández de Sevilla (eds.), La clausura femenina en España: actas del simposium: 1/4-IX-2004, Madrid, Real Centro Universitario Escorial-María Cristina, 2004, II, pp. 1251-1270.

WANG, Luo, "Medieval Saints and Their Miraculous Songs: Ritual Singing, Funerary Piety, and the Construction of Female Sanctity in Thirteenth-Century Liège", Church History, LXXXIX (2020), pp. 509-530.

Wardropper, Bruce, Historia de la poesía lírica a lo divino en la cristiandad occidental, Madrid, Revista de Occidente, 1958.

Zarco Cuevas, Julián, Catálogo de los manuscritos castellanos de la Real Biblioteca de El Escorial, Madrid, Imprenta Helénica, 1924-1929, 3 vols.

ZARrI, Gabriella, "Places and Gestures of Women's Preaching in Quattro- and Cinquecento Italy", en Katherine L. Jansen y Miri Rubin (eds.), Charisma and Religious Authority: Jewish, Christian, and Muslim Preaching, 12001500, Turnhout, Brepols, 2010, pp. 177-193.

—, "Chiara Bugni e Francesco Zorzi suo biografo: Saggio introduttivo", en Reinhold C. Mueller and Gabriella Zarri (eds.), La Vita e i Sermoni di Chiara Bugni, clarissa veneziana (1471-1514), Roma, Edizioni di Storia e Letteratura, 2011, pp. xi-xxxix. 
